The work of the local club in research. How researchers can obtain increased participation for their work. Locals prime concern of raising twins to be individuals while respecting the bonds and blessings of twinship.

The bridge of State Mothers of Twins Clubs which goes across the country. Those States that are formed, and those interested in starting a State Mothers of Twins Club, including Canada. The States forming this bridge number 20 and represent approximately 303 clubs with over 9000 members. Research interest and enthusiasm kindled at State conventions.

The National Organization of Mothers of Twins Clubs, Inc. How its membership is formed from 44 States representing 224 clubs and over 8000 members. The work of National with doctors, scientists, and researchers. Research speakers at national conventions.

How researchers can contact Mothers of Twins Glubs. The great interest by Mothers of Twins Clubs for new research. A partial listing of research completed or being done at the present time. A sampling of Canadian research. Listing of groups for researchers to contact.

The personal growth of mothers of twins through the threefold cord.

How Twin/Lines, USA's only personal paper for MOT and MOTC, provides the vital link of communication for mothers of twins and twin clubs. Why Twin/Lines is able to be at the Twin Congress and what we hope to bring back to share with mothers of twins and twin clubs everywhere.

Mrs. Joyce E. Maxey, 910 26th Street, Marion, Iowa 52302, USA

\section{A DREAM COME TRUE: THE ILLINOIS ORGANIZATION OF MOTHERS OF TWINS GLUBS}

\section{JANE DOJUTREK}

The Illinois Organization of Mothers of Twins Clubs, Inc., Chicago, Illinois, USA

On 20 October 1962, after a year of contacting mothers of twins and mothers of twins clubs throughout Illinois, IOMOTG became a reality for a mother of identical twin girls. At that time, there were 16 charter clubs that joined and 2 membersat-large. IOMOTC now boasts a membership of 27 clubs and I member-at-large for a total of 556 members and a voluntary executive board of 24 officers and chairwomen. As was then and still is, the purpose of IOMOTC is to join together, socially and educationally, member clubs throughout the State of Illinois for the purpose of exchanging information pertaining to the rearing, development, and recognition of the individuality of twins as may be forthcoming from parents, doctors, educators, and other appropriate sources.

Through our prenatal, infancy, toddler, and now pre-teen years, we have accomplished much with regard to research, philanthropic work and, in general, have strengthened the bond of fellowship between mothers of multiple births throughout the United States. Various information and news is exchanged among member clubs through a bimonthly newsletter, a yearbook and a summer and winter packet publication. A state library holds a wealth of information regarding multiple births and club procedures for any member or club wanting its data.

All member clubs are self-governing. Each fall we gather for a Statewide convention, which is held in different cities throughout the State and therefore each club being given a chance to be a hostess. As our slogan "Strength Through Unity" signifies, we anticipate that this First International Congress of Twin Studies will bring a stronger bond of unity between the lay and professional person with regard to multiple births.

Mrs. Jane Dojutrek, 824I W. Berwyn, Chicago, Illinois 60656 , USA

\section{SUPERTWIN RECORD ("BITS 'BOUT MULTIPLES")}

\author{
HELEN KIRK LAUVE \\ Galveston, Texas, USA
}

A fascinating yet productive hobby that began with only details of the delivery of quadruplets by the author's physician-employer in Galveston, Texas, is presented. Files are authentic but by no means inter- 